\title{
Um estudo sobre a implantação de sistemas ERP: pesquisa realizada em grandes empresas industriais
}

\author{
Lindomar Subtil de Oliveira ${ }^{\mathrm{a}^{*}}$, Kazuo Hatakeyama ${ }^{\mathrm{b}}$ \\ a"lindomar@utfpr.edu.br, UTFPR, Brasil \\ bkhatakeyama@uol.com.br, UNISINOS, Brasil
}

\begin{abstract}
Resumo
A notável expansão dos sistemas ERP gerou muitas discussões entre especialistas, pesquisadores e empresários, no intuito de encontrar uma explicação para os diversos casos de sucesso e insucesso na sua implantação. 0 objetivo desse estudo empírico foi identificar nas 50 maiores empresas industriais atuantes no Brasil quais os principais fatores que dificultam ou contribuem para o processo de implantação de sistemas ERP. Tratou-se de uma pesquisa aplicada e exploratória. Além do levantamento bibliográfico, elaborou-se um questionário estruturado com 29 perguntas, o qual foi respondido pelos gestores de T1 (tecnologia de informação) das empresas selecionadas. Os resultados demonstraram que fatores relacionados às dificuldades funcionais do sistema, customização, adaptação aos processos de negócio e carências do ERP no apoio aos planos estratégicos globais foram alguns dos pontos considerados mais complexos. Essencialmente, outros fatores concernentes ao intenso treinamento, engajamento das principais lideranças, fatores humanos, sociais e culturais também foram referidos.
\end{abstract}

Palavras-chave

Sistemas ERP. Projeto de implantação. Fatores críticos de sucesso. Processos de negócio.

\section{Introdução}

No Brasil, com a estabilização da moeda e a abertura de mercado, as empresas começaram a se especializar e foram forçadas a melhorar a competência em todas as áreas, como a produtiva, a financeira, de serviços, custos e logística. Atualmente, as organizações continuam sendo desafiadas a se adequarem às mudanças que ocorrem no meio em que estão inseridas, considerando as necessidades dos clientes, as estratégias de negócios, a concorrência, as leis ambientais, a responsabilidade social, dentre outras coisas. Por isso, para manterem-se competitivas e garantir a perpetuidade do negócio, necessitam cada vez mais de investimentos em inovação tecnológica, atualizações e melhorias contínuas nos processos e modelos de gestão.

Nas últimas décadas, os sistemas integrados de gestão empresarial ERP (Enterprise Resource Planning) tornaram-se oportunamente uma das mais importantes ferramentas utilizadas na gestão de negócios. Esses sistemas contribuem para tornar as empresas mais eficientes, oferecendo resultados primorosos por meio da administração integrada dos recursos, automatização dos processos e melhor fluxo de informações.

Com o intuito de oferecer uma contribuição acerca do assunto ERP, este trabalho apresenta um estudo empírico a respeito dos principais fatores sobre a implantação desses sistemas. Trata-se do resultado de uma pesquisa, a qual teve como objetivo central identificar por meio de um levantamento (tipo survey) junto a 50 grandes empresas industriais atuantes no Brasil quais os principais fatores que dificultam ou contribuem para a implantação de sistemas ERP. Pautando-se nesse objetivo maior, estratificaram-se os aspectos mais específicos que seriam abordados no trabalho, tais como: dificuldades do sistema no atendimento das necessidades do negócio; estratégia de implantação; adequação dos processos de negócios; participação da gerência e dos usuários-chave na equipe de projeto; aspectos culturais, comportamentais e treinamentos; relação com os objetivos estratégicos globais da empresa e o suporte de outras tecnologias. 
0 artigo está dividido em cinco seções, incluindo esta introdução. Na segunda seção é desenvolvida a fundamentação teórica. A terceira traz a metodologia, na qual são detalhadas as etapas da elaboração e aplicação da pesquisa. Na sequência da subdivisão do trabalho são apresentados e discutidos os resultados da pesquisa. Por fim, na seção das considerações desenvolvem-se as argumentações e a análise conclusiva dos pesquisadores.

\section{Sistemas ERP: definição e contextualização}

Em definições correntes, Corrêa, Gianesi e Caon (2001) e Law e Ngai (2007) argumentam que o sistema ERP tem por objetivo suportar as informações gerenciais necessárias aos tomadores de decisões numa organização, auxiliando também na eficiência das operações. Um dos motivos que levaram diversas empresas a adotar o ER, foi justamente a possibilidade de integração de todas as áreas e setores funcionais, visando o compartilhamento de uma mesma base de dados e administrando de maneira eficiente e efetiva os recursos de negócios (ALOINI; DULMIN; MININNO, 2007).

Exemplificando o que esse sistema pode oferecer, na Figura 1 são mostrados os módulos que compõem a maioria dos ERPs mais avançados, com módulos integrados.

Para Turbam, Mclean e Wetherbe (2002), o ERP proporciona soluções que beneficiam e melhoram a eficiência, qualidade e produtividade da empresa, elevando como consequência a satisfação dos clientes. A concepção de Schmitt (2004) e de Souza (2000), que apregoam que o diferencial é a sua capacidade de integração, proporcionando a diminuição dos GAPs (aberturas) ao longo da cadeia produtiva, o controle da empresa como um todo e a atualização tecnológica. Fundamentando-se nos autores citados, assevera-se que o ERP vai além das funções departamentais e oferece uma interface com todas as atividades de rotinas realizadas, desde o pedido de compra, incluindo a logística de entrega e até a pós-venda, com serviços ao cliente.

\subsection{Panorama das pesquisas sobre ERP}

Inúmeros estudos de caso e surveys encontrados na bibliografia nacional apresentam na sua maioria uma abordagem específica, muitas vezes tratando de maneira isolada esses fatores. 0 Quadro 1 apresenta as diferentes contribuições de outras pesquisas nacionais realizadas na área.

Quadro 1. Pesquisas sobre ERP.

\begin{tabular}{|c|c|}
\hline Contribuições/Foco do estudo & Autores \\
\hline $\begin{array}{l}\text { Modismos gerenciais e adoção do ERP, } \\
\text { cultura e comportamento }\end{array}$ & $\begin{array}{l}\text { Fiamengue Neto } \\
\text { (2004), Schmitt } \\
(2004)\end{array}$ \\
\hline $\begin{array}{l}\text { Subsistema estrutural (formal) e cognitivo } \\
\text { (comportamental), Processo de mudança, } \\
\text { resistência e evolução organizacional, } \\
\text { Influência dos fatores subjetivos (pessoas), } \\
\text { Definição dos objetivos empresariais }\end{array}$ & $\begin{array}{l}\text { Fontana (2006), } \\
\text { Jesus e Oliveira } \\
\text { (2007), Cortês e } \\
\text { Lemos (2009) }\end{array}$ \\
\hline $\begin{array}{l}\text { Tecnologia e funcionalidades do sistema, } \\
\text { Dificuldades de adaptação, análise e } \\
\text { reengenharia dos processos de negócios }\end{array}$ & $\begin{array}{l}\text { Morgado (2007), } \\
\text { Mello e Bandeira } \\
(2007)\end{array}$ \\
\hline $\begin{array}{l}\text { Alinhamento estratégico da Tl, Estratégia } \\
\text { corporativa }\end{array}$ & $\begin{array}{l}\text { Laurindo (2002 a), } \\
\text { Souza et al. (2010), } \\
\text { Saccol (2004) }\end{array}$ \\
\hline $\begin{array}{l}\text { Benefícios e aumento da produtividade, } \\
\text { Avaliação de investimentos em } \mathrm{Tl}\end{array}$ & Souza et al. (2010) \\
\hline $\begin{array}{l}\text { Estratégia e etapas de implantação do } \\
\text { projeto, Treinamentos; Comprometimento e } \\
\text { participação dos usuários e direção }\end{array}$ & $\begin{array}{l}\text { Cortês e Lemos } \\
\text { (2009), Mello e } \\
\text { Bandeira (2007) }\end{array}$ \\
\hline $\begin{array}{l}\text { Gestão de riscos do projeto, Fatores críticos } \\
\text { de sucesso }\end{array}$ & $\begin{array}{l}\text { Gambôa, Caputo } \\
\text { e Bresciani Filho } \\
(2004)\end{array}$ \\
\hline
\end{tabular}

Fonte: levantamento bibliográfico.

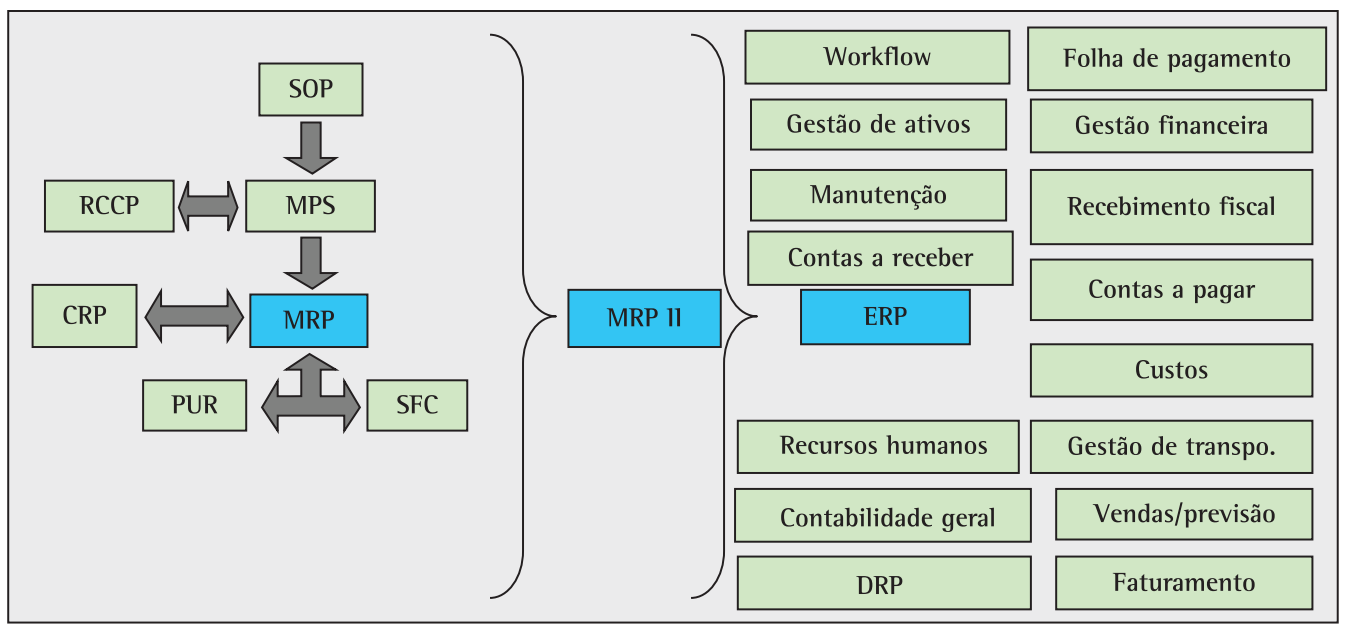

Figura 1. Módulos que compõem o ERP. Fonte: adaptado de Corrêa, Gianesi e Caon, (2001) 
Adicionalmente ao quadro apresentado, ressalta-se que o presente estudo difere e contribui por considerar um viés complementar aos aspectos ilustrados, principalmente por ter sido realizado junto a um significativo grupo de empresas industriais.

\subsection{Características, fatores intervenientes na implantação e as mudanças geradas}

Devido a sua complexidade, elevados custos de investimento, barreiras de implantação e imposição de mudanças radicais na organização, esses sistemas têm apresentado significativas falhas (LAW; NGAl, 2007). Um aspecto salutar para que o ERP alcance eficazmente os objetivos organizacionais é o amadurecimento e preparação da empresa para as transformações, definindo claramente as necessidades e compatibilizando-as aos objetivos do negócio (ALOINI; DULMIN; MININNO, 2007; SAMMON; ADAM, 2010; LAW; NGAl, 2007). 0 sucesso do ERP requer a capacitação das pessoas para o enfrentamento dos desafios tecnológicos e a mútua adaptação entre a tecnologia da informação e o ambiente organizacional (WANG et al., 2008).

Além disso, diversos outros fatores podem ser enaltecidos na implantação desses sistemas. No trabalho de Padilha e Marins (2002), complementando-se também com a visão de outros autores, são apresentadas algumas características e pontos cruciais relacionados ao ERP:

Pacotes comerciais: Os fornecedores de software têm se esforçado para unir seus sistemas aos nichos de mercado específicos. Normalmente são oferecidos como pacotes comerciais fechados que auxiliam na integração das funções, contudo obrigam a empresa compradora a adequar-se a esses softwares (ALOINI; DULMIN; MININNO, 2007; CHOU; CHANG, 2008). Essa é uma estratégia na qual esses sistemas

[...] não são desenvolvidos para clientes específicos, procurando atender a requisitos genéricos do maior número possível de empresas, justamente para explorar o ganho de escala em seu desenvolvimento. (SOUZA, 2000, p. 13).

Adequação, funcionalidades e localização: A aquisição de um ERP pode gerar duas situações: primeiro é o processo de adequá-lo às exigências organizacionais por meio da parametrização; segundo é o processo de personalização ou customização, o qual consiste na acomodação às necessidades específicas da empresa. Apesar dessa possibilidade oferecida, salienta-se que ainda há, nos diversos países, a dificuldade desses sistemas se adaptarem à legislação, à economia, à política e à cultura locais. É crucial analisar os riscos e impactos dessas mudanças. Corroborando, Yen e Sheu (2004) e Avison e Malaurent
(2007) explicam que peculiaridades do país como língua, estilo gerencial e as políticas governamentais também influenciam o processo de implementação, principalmente quando em paises distintos, com leis diferentes, afetando assim a própria configuração e manutenção do software.

Custos elevados: Os custos predominantemente estão relacionados à infraestrutura de hardware e software, consultorias, treinamentos, contratação de pessoal especializado e outros que muitas vezes não aparecem durante o ciclo de vida do sistema (ALOINI; DULMIN; MININNO, 2007). Para Yen e Sheu (2004) e Kruse (2006), o que se denota é a ausência de um planejamento rigoroso, capaz de antever os gastos com as customizações, o que faz com que, por consequência, esses acabem gerando maiores custos, que ultrapassam o orçamento estipulado. Em muitos casos, os fornecedores não oferecem suporte para rotinas empresariais altamente customizadas, o que concorre igualmente para elevar os gastos (SOUZA, 2000).

Atualização: Oferecem a possibilidade de upgrades, que são melhorias importantes e necessárias incorporadas ao sistema, que atualizam para as novas versões, para adequar-se a mudanças (ALOINI; DULMIN; MININNO, 2007). Entretanto, esse aspecto também tem recebido críticas, por situações em que dificuldades na flexibilização do sistema para se ajustar à realidade empresarial, responder às variações, ao crescimento do negócio e a estratégias competitivas globais se apresentaram (COMPUTERWORLD, 2005).

Prazos e orçamentos: 0 projeto pode falhar por não se realizar no prazo e orçamento previsto (ALOINI; DULMIN; MININNO, 2007). Esse fator, segundo Padilha e Marins (2002), pode ocorrer devido a troca frequente de pessoal na empresa, escassez de treinamento, resistência, qualidade da consultoria, limitações técnicas e nas afinidades com as demais tecnologias.

\subsection{Reengenharia e adaptação aos processos}

Como forma de melhorar a integração das atividades, Hammer (2002) aponta o ERP como um sistema que suporta todos os processos de negócios. Para Sammon e Adam (2010), a empresa corre o risco de não ser bem sucedida na implantação quando não tem claro o entendimento dos seus processos. Ainda,

[...] a implementação do ERP é importante ser dirigida, em primeiro lugar, para a criação de novos desenhos de processos, e somente então para a instalação de um sistema de software capaz de lhes dar suporte. (HAMMER, 2002, p. 83). 
0 autor Davenport (1994) defende a reengenharia de processos explicando que se trata de uma estratégia que visa melhorar também o desempenho financeiro da empresa, principalmente pela redução de custos das operações. Na sua visão, a reengenharia é uma forma radicalmente nova de se gerenciar, enquanto que a melhoria nos processos implica somente no aumento da eficiência e da eficácia na realização do mesmo. Para Jacobs e Bendoly (2002), a reengenharia não é para ser, apenas, alocada ao sistema, ela deve promover a efetiva implementação das melhores práticas. Nesse sentido, Chou e Chang (2008) argumentam que se tornou crítico harmonizar e alinhar os processos e funções organizacionais ao ERP.

\subsection{A influência dos fatores humanos}

Os fatores cruciais relacionados à implantação do ERP não se limitam, apenas, às dificuldades tecnológicas, também incluem a sensibilidade e receptividade com que são tratadas as mudanças trazidas pelo sistema, os problemas de falta de comprometimento (envolvimento limitado) e as falhas na comunicação entre as pessoas envolvidas (AVISON; MALAURENT, 2007). De acordo com Sammon e Adam (2010), é importante que haja participação de todos os atores organizacionais relevantes, a fim de que sejam treinados e preparados para identificar os potenciais problemas.

Na visão preconizada por Kruse (2006) e por Avison e Malaurent (2007), os aspectos sociais, humanos e culturais constituem o principal elemento para o alcance de sucesso. Logo, devido à relevância do fator humano, o processo de implantação compreende principalmente mudanças no comportamento da organização. Nesse aspecto, o corpo gerencial tem a responsabilidade de assegurar que o sistema trará melhorias operacionais ao trabalho e fluxo de informações e transmitir isso às demais pessoas, de forma que todos tenham confiança, saibam entender e utilizar a tecnologia a seu favor. Nesse sentido, Calisir e Calisir (2004) argumentam que é fundamental dedicar uma atenção maior aos usuários, pois a satisfação deles tende a aumentar se acreditarem que com os benefícios proporcionados pelo sistema eles irão melhorar seu desempenho e produtividade.

\subsection{Fatores críticos de sucesso (FCS)}

Uma gama de autores, entre eles Aloini, Dulmin e Mininno (2007) e Wang et al. (2008), tem trabalhos publicados a respeito dos FCS. Na acepção de Xue et al. (2005) entende-se por fatores críticos de sucesso (FCS) aquelas poucas áreas consideradas chave na organização, nas quais as atividades funcionam corretamente para obter uma implementação bem-sucedida do sistema. Por isso, identificar essas áreas e começar por elas a implantação aumenta as probabilidades de sucesso. Corroborando, a definição original para os FCS foi apresentada por Rockart (1979), apud Laurindo et al. (2001, p. 11), e seu conceito refere-se ao "[...] número limitado de áreas nas quais os resultados, se satisfatórios, asseguram o desempenho competitivo bem-sucedido para a organização".

Verifica-se que não basta apenas se amparar nos resultados de empresas que lograram êxito, pois cada organização apresenta uma característica impar, como: tamanho, tipo de negócio, mercado de atuação, entre outros fatores que certamente vão influenciar na escolha e extensão da tecnologia. Para Aloini, Dulmin e Mininno (2007), os fatores críticos incluem aspectos de gerenciamento e tecnologia. Para se chegar a um método efetivo de avaliação de riscos, considera-se vários pormenores, entre eles mercado, finanças, operacional, organizacional e negócios. Assim sendo, recomenda-se analisar com cuidado todas as variáveis críticas de riscos que envolvem o projeto de implantação. Umble, Haft e Umble (2002, p. 244-247), citando outros trabalhos, arrolam os FCS com relação à implantação dos sistemas ERP.

\subsubsection{Objetivos estratégicos e gerenciamento do projeto}

0 sucesso na implantação do ERP requer foco, empenho da organização e uma abordagem formalizada no gerenciamento do projeto (SAMMON; ADAM, 2010). Os maiores problemas não advêm necessariamente das aptidões e funcionalidades do software, mas da falta de uma metodologia documentada de implantação, que já tenha sido previamente testada e aprovada (KRUSE, 2006). Isso requer o estabelecimento dos planos de trabalho, planejamento de recursos e necessidades do negócio.

Uma definição explícita desses planos e objetivos certamente contribuirá para um escopo de projeto mais engendrado, o qual preestabelecerá as dificuldades que comprometem o orçamento, bem como o processo de implementação.

Denota-se ainda a importância da formação de uma equipe qualificada, com habilidades de liderança e execução. Essa equipe é relevante, uma vez que os membros podem trocar experiências internas e externas com especialistas, além de tornarem-se responsáveis pelas diversas atividades relacionadas, como: tomadas de decisões, detalhamento do projeto, mediação de conflitos entre os stackholders, elaboração dos planos globais dos programas, comunicação com todas as áreas e direção da empresa, além de determinarem os 
cronogramas e cooperarem para que todos os recursos estejam disponiveis (Wang et al., 2008; LAW; NGAl, 2007; ALOINI; DULMIN; MININNO, 2007).

\subsubsection{Comprometimento da alta direção}

A implementação exige uma liderança robusta, envolvimento efetivo da alta direção, bem como a formação de um comitê executivo de planejamento, pois ambos auxiliam a minimizar os riscos, resistências e o temor de mudanças (LAW; NGAl, 2007; KRUSE, 2006).

\subsubsection{Gerenciamento da mudança}

Os autores Umble, Haft e Umble (2002) afirmam que a estrutura organizacional e os procedimentos encontrados em muitas empresas não são compatíveis com a estrutura e tipos de informação oferecidas pelos ERP. Essas características fazem com que esses sistemas introduzam a sua própria lógica de funcionamento e imprimam mudanças nas estratégias empresariais.

\subsubsection{Acuracidade}

Para obter resultados eficazes é fundamental que os dados de entrada que geram as informações sejam precisos e confiáveis. É conveniente que os usuários estejam instruídos a utilizarem corretamente o programa. 0 papel da empresa é resguardar para que todos estejam comprometidos com as mudanças e passem a trabalhar integralmente no âmbito do novo sistema, evitando assim manter o uso paralelo do sistema antigo.

\subsubsection{Treinamento e educação}

Para Sammon e Adam (2010) e Aloini, Dulmin e Mininno (2007), este é provavelmente o mais importante FCS na implementação do ERP e um dos motivos por que muitos projetos falham. Para Umble, Haft e Umble (2002), o treinamento impacta diretamente na construção do conhecimento e aptidão das pessoas. É comum o fato de muitos executivos descuidarem quanto ao nível necessário de capacitação dos usuários e em relação aos custos inerentes a esse processo. Conforme declaram, o objetivo é que ela ocorra muito antes do sistema começar a funcionar e sugerem que os gastos pertinentes em todas as fases do projeto, auxiliam para elevar para $80 \%$ as probabilidades de sucesso.

\subsubsection{Avaliação de desempenho}

É importante mensurar a performance do sistema desde o princípio da implantação, incluindo-se avaliações dos tempos de entrega, margens de lucro e desempenho de vendedores. Para Law e Ngai (2007), o sucesso é mensurado também pela satisfação dos usuários. Por isso, é crucial que todos executem de modo eficaz suas atividades e a empresa premie os colaboradores oferecendo recompensa pelos resultados alcançados.

\subsubsection{Implementação múltipla}

Trata-se de outro ponto essencial, pois a implantação em várias áreas pode enfrentar problemas culturais, uma vez que a dificuldade consiste em relacionar a padronização da empresa com a otimização local de cada área.

\section{Metodologia}

0 presente estudo classificou-se como quantitativo, aplicado e exploratório. Para roteiro de pesquisa e fundamentação metodológica, foram utilizados Lakatos e Marconi (2001), Gil (1999) e Luna (2002).

\subsection{Amostragem, classificação das empresas e limitação do estudo}

A fim de construir o referencial teórico, foi realizada uma pesquisa na literatura para identificar o estado da arte sobre o assunto. Pesquisaram-se dissertações de mestrado, teses de doutorado e artigos, além de diversos outros materiais.

A população amostrada constituiu-se das 50 maiores empresas industriais em operação no território brasileiro, classificadas em ordem decrescente por valor em vendas, conforme a relação das "500 maiores e melhores empresas (população objeto)" publicada pela revista Exame (2005). 0 critério de escolha foi justificado por serem organizações de grande porte e de significativa representatividade econômica no mercado nacional. Acrescenta-se o fato de serem empresas oportunas, para se obter um benchmarking daquilo que está se fazendo, "ou como estas estão agindo" com relação à implantação e uso dos sistemas ERP. Destarte, atribui-se a essas empresas maior experiência com implantações, visto que normalmente contemplam mais de um tipo de sistema implantados em diferentes países. Assim, é possível identificar as principais dificuldades enfrentadas por elas, bem como verificar os benefícios auferidos com a utilização do ERP.

A amostragem caracterizou-se como não probabilística e por acessibilidade, sendo que esta foi uma limitação do estudo, uma vez que os dados não podem ser usados para qualquer outra generalização. Contudo, é possivel afirmar que os resultados obtidos serviram para indicar uma tendência quanto a sua aplicação ao restante total da população. 


\subsection{Instrumentos de pesquisa}

Como instrumento técnico de coleta de dados elaborou-se um questionário (Apêndice $A$ ) estruturado com 29 perguntas fechadas. A construção do modelo de pesquisa e o dimensionamento das questões, fundamentaram-se no referencial expresso no Quadro 2.

As perguntas foram divididas basicamente em cinco módulos, um abordando os perfis das empresas e os outros quatro relacionados aos objetivos da pesquisa. Formularam-se algumas questões utilizando-se a escala Likert, a qual se caracteriza por exprimir um conjunto de alternativas em que o respondente é levado a concordar ou discordar em relação ao seu conteúdo, para isso atribuindo um valor em escala que variava de 1 (pouca importância) a 5 (grande importância).

\subsection{Respondentes, validação do questionário e desenrolar da pesquisa}

A etapa inicial consistiu num primeiro contato telefônico com o público-alvo definido pelos pesquisadores para responder o questionário, que nesse caso determinou-se seriam os gerentes ou líderes responsáveis pela área de $\mathrm{Tl} /$ informática. Posteriormente foi encaminhado um e-mail a essas pessoas/empresas, juntamente com um ofício da universidade apresentando o pesquisador e também o

Quadro 2. Dimensionamento das questões da pesquisa.

\begin{tabular}{|l|l|}
\hline Escopo do estudo/Grupo de questões & \multicolumn{1}{|c|}{ Base referencial } \\
\hline Caracterização da empresa (1 a 4) & $\begin{array}{l}\text { elaborado pelos próprios } \\
\text { autores (OLIVEIRA, 2006) }\end{array}$ \\
\hline $\begin{array}{l}\text { Dificuldades quanto às necessidades } \\
\text { do negócio e ao alinhamento } \\
\text { estratégico (5 a 8) }\end{array}$ & Laurindo (2002b) \\
\hline $\begin{array}{l}\text { Mudanças nos processos, visão do } \\
\text { ERP, conhecimento dos usuários, } \\
\text { tendências (9 a 12) }\end{array}$ & $\begin{array}{l}\text { Cavalcanti (2001), } \\
\text { elaborado pelos próprios } \\
\text { autores (OLIVEIRA, 2006), } \\
\text { Silva (2005) }\end{array}$ \\
\hline $\begin{array}{l}\text { Tipo de ERP, investimentos totais, } \\
\text { tempo, estudo de viabilidade de } \\
\text { implantação (13 a 17) }\end{array}$ & $\begin{array}{l}\text { elaborado pelos próprios } \\
\text { autores (OLIVEIRA, 2006), } \\
\text { Cavalcanti (2001) }\end{array}$ \\
\hline $\begin{array}{l}\text { Envolvimento e participação no } \\
\text { projeto, implantação bem-sucedida } \\
\text { (18 e 19) }\end{array}$ & $\begin{array}{l}\text { Fiamengue Neto (2004), } \\
\text { Souza (2000), Schmitt } \\
\text { (2004), Macêdo (2005) }\end{array}$ \\
\hline $\begin{array}{l}\text { Investimentos, interação e cultura } \\
\text { (20 e 21) }\end{array}$ & $\begin{array}{l}\text { elaborado pelos próprios } \\
\text { autores (OLIVElRA, 2006), } \\
\text { Fiamengue Neto (2004) }\end{array}$ \\
\hline $\begin{array}{l}\text { Comportamento e treinamento dos } \\
\text { usuários (22 e 23) }\end{array}$ & $\begin{array}{l}\text { Schmitt (2004), Silva } \\
\text { (2005), Macêdo (2005) }\end{array}$ \\
\hline Suporte de outras tecnologias (24) & $\begin{array}{l}\text { Fortulan e Gonçalves } \\
\text { Filho (2005), Norris et al. } \\
\text { (2001) }\end{array}$ \\
\hline $\begin{array}{l}\text { Benefícios do ERP quanto a: } \\
\text { integração com outros sistemas, } \\
\text { processos de trabalho, estratégias, } \\
\text { gerenciamento da fábrica e } \\
\text { atendimento aos clientes (25 a 29) }\end{array}$ & $\begin{array}{l}\text { Macêdo (2005), Corrêa, } \\
\text { Gianesi e Caon (2001), } \\
\text { Souza (2000) }\end{array}$ \\
\hline
\end{tabular}

Fonte: pesquisa bibliográfica realizada pelos autores (OLIVEIRA, 2006). questionário. Para formalizar o contato, esses mesmos documentos foram encaminhados via correio para as referidas empresas. Segundo Rea e Parker (2000, p. 81),

[...] é razoável esperar que esse procedimento produza um índice de resposta de 50\% a 60\%. Esse índice pode ser considerado aceitável para a análise e o relato das constatações.

Ainda com relação ao questionário, buscou-se validá-lo por meio do envio, inicialmente, para três empresas, as quais representaram $6 \%$ do total de 50 empresas. Foi solicitado que os respondentes apontassem possíveis dificuldades no preenchimento e, após o retorno, como não houve nenhuma mudança sugerida, o mesmo foi considerado apto para ser aplicado ao restante das empresas.

$\mathrm{Na}$ sequência procurou-se manter o relacionamento contínuo por meio de inúmeros e-mails, até findar o prazo anunciado para a consolidação das respostas. Numa avaliação geral quanto à receptividade das empresas, ela foi considerada satisfatória, alguns respondentes até dedicaram um esforço maior para explicar o processo de transição e mudança pelo qual a empresa estava passando no momento com relação à troca de sistema.

Entretanto, houve empresas que relutaram em responder o questionário porque não tinham autorização da matriz, localizada em outro país. Outras não responderam alegando que haviam questões estratégicas para o negócio e que não poderiam ser divulgadas. No total, foram dez organizações que se negaram a responder; outras dez, mesmo tendo sido tentados vários contatos posteriores, não manifestaram o motivo.

\section{Apresentação dos resultados}

Primeiramente, com relação à devolutiva da pesquisa, dos 50 questionários enviados, 30 (60\%) foram respondidos. 0 Quadro 3 apresenta a distribuição dessas empresas por segmento de atuação. Visando garantir o sigilo e a ética perante as empresas respondentes, o nome delas não foi divulgado, com as informações recebendo tratamento generalizado.

Para efeito de exposição dos resultados e conforme a metodologia, todas as questões foram ponderadas

Quadro 3. Distribuição das empresas.

\begin{tabular}{|l|c|}
\hline \multicolumn{1}{|c|}{ Setor/segmento de atuação } & Quant. de empresas \\
\hline Automotivo & 9 \\
\hline Alimentos, bebidas e fumo & 7 \\
\hline Química e petroquímica & 6 \\
\hline Siderurgia e metalurgia & 6 \\
\hline Construção & 1 \\
\hline Eletroeletrônico & 1 \\
\hline Total de empresas & 30 \\
\hline
\end{tabular}

Fonte: dados da pesquisa (2006). 
de forma quantitativa e representadas por tabelas e quadros. Ressalta-se que se priorizou pela análise dos maiores percentuais, conforme o grau de importância (1 a 5) encontrado em cada questão. Assim, adotou-se como critério ordenar e discorrer sobre os itens que tiveram maior frequência de citação pelas empresas.

A pesquisa estruturou-se em cinco blocos de questões, sendo que o primeiro (perguntas 1 a 4), apresentado na Figura 2, diagnosticou como estava constituído o perfil das empresas.

Essas características serviram para ratificar a relevância das empresas, bem como a riqueza de informações obtidas.

\subsection{Dificuldades de adaptação às necessidades do negócio}

No segundo módulo (questões 5 a 8), descrito na Tabela 1, foram levantadas as dificuldades mais evidentes em relação ao sistema ERP.

Dentre as dificuldades evidenciadas como de grande importância ou entre muita e moderada importância destacaram-se:

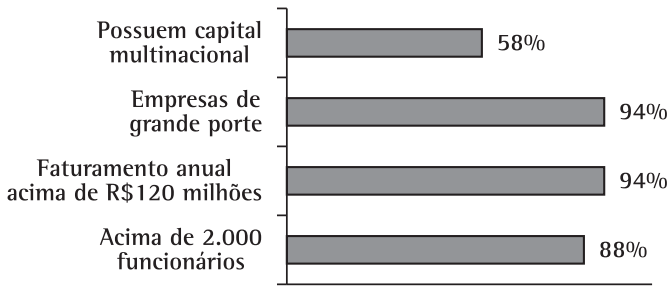

Figura 2. Perfil das empresas. Fonte: dados da pesquisa (2006).
- Dificuldade de adaptação à economia/legislação brasileira (37\%). Esse foi um dos fatores que se sobressaíram, apontado como crucial na implantação. A maioria das empresas pesquisadas é formada por multinacionais, dessa forma elas acabam sofrendo maior influência da cultura econômica do país, principalmente no Brasil, cuja carga tributária é elevada e as mudanças na legislação, frequentes. Nesse sentido, a inflexibilidade do sistema em compatibilizar e se adaptar às mudanças da economia e da legislação do país limita a utilização em muitas áreas da empresa;

- Identificação e adaptação aos processos de negócios (57\%). Esse percentual representou a opinião da maior parcela dos respondentes, além de indicar que o correto delineamento dos processos é requisito crucial para o alcance dos resultados;

- Altos custos de implantação (23\% e 20\%). Condiz com o que foi apresentado pela literatura, considerando que os investimentos são impactantes e decisivos no projeto, bem como o cumprimento do orçamento planejado. Coadunando com essas informações, outra questão investigou sobre valores anuais ( $\mathrm{R} \$$ ) gastos com treinamentos. A maioria (27\%) informou ter gasto entre 201 e 500 mil reais; $21 \%$ apontaram outros valores em treinamentos; $13 \%$ não quiseram ou não souberam mencionar os totais despendidos; $18 \%$ gastaram menos de 70 mil reais e para $21 \%$ os dispêndios giraram entre 71 e 200 mil reais;

- Tornar o sistema amigável e de fácil acesso (40\% e 37\%). Com efeito, esse é um ponto crítico, pois as características de funcionalidade e usabilidade afetam diretamente o desempenho dos usuários.

Tabela 1. Dificuldades gerais pertinentes aos sistemas ERP.

\begin{tabular}{|c|c|c|c|c|c|}
\hline Itens de análise & Grande $(\%)$ & $\begin{array}{l}\text { Entre muito e } \\
\text { moderada (\%) }\end{array}$ & $\begin{array}{l}\text { Mediana } \\
(\%)\end{array}$ & $\begin{array}{c}\text { Entre mediana e } \\
\text { pouca }(\%)\end{array}$ & $\begin{array}{c}\text { Pouca } \\
(\%)\end{array}$ \\
\hline Adaptação à economia/legislação & 37 & 20 & 7 & 13 & 23 \\
\hline Qualificação técnica das pessoas & 7 & 23 & 33 & 17 & 20 \\
\hline 1dentificação/adaptação aos processos de negócios & 57 & 17 & 17 & 3 & 6 \\
\hline Interface com outros módulos & 17 & 30 & 13 & 23 & 17 \\
\hline Altos custos de implantação & 23 & 20 & 17 & 20 & 20 \\
\hline Tornar sistema amigável e de fácil acesso & 40 & 37 & 13 & 7 & 3 \\
\hline Burocracia/formulário/requisição & 7 & 3 & 30 & 23 & 37 \\
\hline Necessidade de outros programas & 10 & 17 & 37 & 27 & 9 \\
\hline Parametrização/customização & 43 & 37 & 3 & 17 & 0 \\
\hline Implantação parcial & 13 & 23 & 13 & 17 & 34 \\
\hline Não tem todos os recursos necessários & 34 & 23 & 13 & 20 & 10 \\
\hline Confiabilidade dos dados/informações & 44 & 10 & 13 & 3 & 30 \\
\hline Tempo de resposta aos clientes & 23 & 30 & 17 & 17 & 13 \\
\hline Atualizações (upgrades) & 17 & 23 & 23 & 17 & 20 \\
\hline Adaptação (best practices) & 33 & 20 & 13 & 27 & 7 \\
\hline Visão de longo prazo e resultados neg. & 53 & 27 & 7 & 7 & 6 \\
\hline Relacionamento sustentável c/clientes & 20 & 17 & 23 & 20 & 20 \\
\hline Competição em escala global & 40 & 17 & 20 & 13 & 10 \\
\hline Mudanças nos modelos gerenciais & 13 & 20 & 10 & 17 & 40 \\
\hline Adaptação ao crescimento do negócio & 10 & 27 & 33 & 23 & 7 \\
\hline
\end{tabular}

Fonte: dados da pesquisa (2006). 
Além do que essa dificuldade de operacionalização resulta, consequentemente, em maior resistência à sua adoção;

- Parametrização/customização (43\% e 37\%). Revelou-se de sublime importância para a maioria das firmas e comprovou ser um dos aspectos mais destacados, necessitando tremendo empenho dos empresários para adequar a empresa à rotina de funcionamento do sistema e para adaptá-lo no atendimento aos processos de negócios;

- Adaptação das melhores práticas de negócios (33\% e 20\%). Apesar de não ser um dos principais benefícios do ERP, observou-se que as empresas ainda encontram dificuldades pelo fato de o sistema não atender completamente às expectativas e às melhores práticas de negócios;

- Visão de longo prazo e alinhamento às estratégias competitivas (53\% e 27\%). Esses números demonstraram mais uma das notáveis dificuldades apresentadas pelos sistemas ERP. Assim como se verificou na teoria, confirmou-se na prática que o ERP não oferece subsídios completos para decisões estratégicas e de longo prazo;

- Competição em escala global (40\%). Analogamente, esse resultado corrobora os anteriores: as empresas afirmaram com veemência que, ante um aparato competitivo global, o sistema apresenta entraves na parte organizacional;

- Interface do sistema com outros módulos (30\%). Para uma quantidade significativa de empresas, a adversidade de interface com outros módulos foi considerada entre como de muito a média importância. Atribui-se esse resultado, possivelmente, às dificuldades que as empresas enfrentam atualmente com o sistema; e

- Tempo de resposta aos clientes (30\% e 23\%). Como economia de tempo significa ganhos financeiros, denota-se que à rapidez no atendimento aos clientes atribui-se uma importância primordial. Entretanto, essa função revelou-se um dos aspectos críticos e difíceis durante a sua operacionalização. Ademais, arrolam-se outros itens que tiveram percentuais de destaque: Não disponibiliza todos os recursos necessários ao negócio (34\% e 23\%); e Confiabilidade dos dados e informações (44\%).

Analisando os demais resultados no que diz respeito às dificuldades menos importantes, três fatores se sobressaíram:

Burocracia com relação a formulários e requisições (37\%); Implantação parcial (34\%); e Mudanças nos modelos gerenciais (40\%). Este último demonstrou que as mudanças em nível gerencial não causam tantos impactos quanto nos níveis operacionais. lsso refletiu a própria maturidade das empresas e a preparação com que os gerentes delas encaram as inovações tecnológicas.
Entre os fatores que receberam peso entre mediana e pouca importância, conforme percentuais demonstrados na Tabela 1, notabilizaram-se:

- Qualificação técnica (33\%). 0 resultado demonstrou uma significância não tão expressiva quanto a apresentada na literatura, a qual ressalta a preparação das pessoas como requisito de extrema importância para utilizar-se eficientemente o sistema. É possível comparar e compreender essa resposta a partir da ênfase atribuída ao treinamento. Em consequência, conclui-se que com treinamento intenso obtém-se maior qualificação dos colaboradores;

- Necessidade de outros programas para suprir a carência de relatórios gerenciais (37\% e 27\%). Esses aspectos também não foram considerados barreiras, haja vista que todas as empresas, praticamente, já utilizam outros tipos de sistemas específicos no suporte aos relatórios gerenciais. Dentre os mais utilizados, a pesquisa apontou que 90\% usam a tecnologia EDI, 87\%, Data Warehouse, seguidos de 70\% que utilizam Bl e 67\%, MRP; e

- Dificuldades de atualização do sistema (upgrades) (23\% e 17\%). Apesar de diversos autores opinarem sobre a relevância da atualização, verificou-se que não houve uma notável expressividade de empresas que o consideraram como aspecto relevante. Adicionalmente, receberam mediana importância: Relacionamento sustentável com os clientes (23\% e $20 \%$ ) e Adaptação ao crescimento do negócio e às novas tecnologias (33\% e 23\%).

\subsection{Aspectos relevantes do projeto}

0 terceiro módulo de questões ( 9 a 19) foi direcionado para os pontos essenciais do projeto de implantação, que contribuem para atingir os resultados empresariais. Na Tabela 2 são demonstrados os percentuais das respostas conforme o grau de concordância dos respondentes.

Concernente aos investimentos e tempo de implantação, dispostos na Tabela 3, verificou-se que a maior representatividade de empresas dispendeu valores diferentes dos listados pela pesquisa, que $16 \%$ delas não revelaram o quanto foi investido e que, das demais, 51\% informaram valores entre 20 e 45 mil reais. Outras mencionaram dispêndio entre 1 e 4 milhões e o restante permaneceu num patamar entre 10 e 20 milhões de reais.

Destacando-se os percentuais mais relevantes sobre o tempo de implantação, constatou-se que para um total de 50\% o projeto transcorreu num prazo entre 13 e 24 meses e que um número considerável de empresas (30\%) implantou o projeto num período entre 25 e 48 meses.

Quanto aos aspectos que favorecem uma implantação bem-sucedida, a Tabela 4 alude mais a alguns resultados levantados conforme os maiores 
Tabela 2. Aspectos significativos do projeto.

\begin{tabular}{lccc}
\multicolumn{1}{c}{ Questão } & $\begin{array}{c}\text { Concordam } \\
(\%)\end{array}$ & $\begin{array}{c}\text { Concordam } \\
\text { parcialmente (\%) }\end{array}$ & $\begin{array}{c}\text { Discordam } \\
(\%)\end{array}$ \\
\hline Necessidade do ERP & 87 & 13 & 0 \\
Tendência do ERP & 77 & 23 & 0 \\
Pleno conhecimento dos usuários & 43 & 57 & 0 \\
Reengenharia dos processos concomitante à implantação & 56 & 44 & 0 \\
Aplicação de todas as fases (apresentadas) do estudo de viabilidade de implantação & 90 & 10 & 30 \\
Comprometimento e participação efetiva dos usuários-chave na equipe do projeto & 37 & 33 & 0 \\
Participação da gerência e alta direção & 80 & 20 & 27 \\
Reduziu o número de funcionários & 3 & 27 & 70 \\
\hline
\end{tabular}

Fonte: dados da pesquisa (2006).

percentuais de grande ou entre muita e moderada importância.

- Implantação do sistema planejada por módulos (33\%); e

- Treinamento prévio dos funcionários (30\% e 30\%). Os percentuais atestam que a qualificação dos usuários é indispensável para alcançar resultados mais benéficos. Nesse mesmo viés, confirmou-se em outra abordagem que a formação de grupos na implantação foi compactuada por $73 \%$ das empresas; $63 \%$ avaliaram o nível de treinamento; e $57 \%$ consentiram que a insuficiência de treinamento prejudica sobremaneira o desempenho da organização.

Em face dos itens de pouca ou entre mediana e pouca importância, visualizados na Tabela 4, ressaltaram-se os seguintes:

- Implantação total, aquisição de pacotes padrões de softwares (27\% e 23\%); e

- Contratação de uma consultoria (30\% e 17\%). 0 fato de se optar ou não por uma consultoria depende do nível de conhecimento e empenho da empresa no que concerne à disponibilidade e qualificação das pessoas para atuar na implantação. Ademais, exige uma cultura organizacional sólida para aceitar os desafios e mudanças, bem como segurança, experiência e aporte de recursos financeiros. Em contrapartida, destacou-se que $27 \%$ atribuíram grande importância ao papel da consultoria.

\subsection{Fatores culturais e comportamentais}

Essas informações foram abordadas no quarto módulo de perguntas (20 a 23) e são apresentadas na Tabela 5.

Não obstante a maioria estar satisfeita (87\%), denota-se que ainda paira no meio empresarial extrema dificuldade de adaptação das pessoas. Em geral, não é um processo simples fazer com que as pessoas abandonem uma prática já estabelecida e passem a utilizar um sistema em toda a sua potencialidade. Corroborando, para 67\% houve resistência das pessoas em relação às mudanças.
Tabela 3. Investimento e tempo de implantação.

\begin{tabular}{lclc}
\hline \multicolumn{1}{c}{ Investimento no projeto } & $\%$ & $\begin{array}{l}\text { Tempo (meses) } \\
\text { de implantação }\end{array}$ & $\%$ \\
\hline Outros valores (diferentes dos apresentados) & 67 & Entre 6 e 12 & 7 \\
Entre 400 e 600 mil reais & 7 & Entre 13 e 24 & 50 \\
Entre 600 mil e 1 milhão de reais & 16 & Entre 25 e 48 & 30 \\
Não informaram & 10 & Mais de 48 & 13 \\
\hline
\end{tabular}

Fonte: dados da pesquisa (2006).

Tabela 4. Fatores ponderáveis na implantação.

\begin{tabular}{lccccc}
\hline $\begin{array}{c}\text { Itens de } \\
\text { análise }\end{array}$ & $\begin{array}{c}\text { Grande } \\
(\%)\end{array}$ & $\begin{array}{c}\text { Entre } \\
\text { muita e } \\
\text { moderada } \\
(\%)\end{array}$ & $\begin{array}{c}\text { Mediana } \\
(\%)\end{array}$ & $\begin{array}{c}\text { Entre } \\
\text { mediana } \\
\text { e pouca } \\
(\%)\end{array}$ & $\begin{array}{c}\text { Pouca } \\
(\%)\end{array}$ \\
\hline $\begin{array}{l}\text { Implantação } \\
\text { por módulos }\end{array}$ & 33 & 17 & 7 & 17 & 26 \\
$\begin{array}{l}\text { Implantação } \\
\text { total } \\
\text { (pacotes) }\end{array}$ & 13 & 20 & 17 & 23 & 27 \\
$\begin{array}{l}\text { Consultoria } \\
\text { para } \\
\text { implantação }\end{array}$ & 27 & 9 & 17 & 30 & 17 \\
$\begin{array}{l}\text { Cumprir } \\
\text { orçamento } \\
\text { planejado }\end{array}$ & 17 & 23 & 30 & 7 & 23 \\
$\begin{array}{l}\text { Treinamento } \\
\text { prévio }\end{array}$ & 30 & 30 & 20 & 13 & 7 \\
\hline
\end{tabular}

Fonte: dados da pesquisa (2006).

Tabela 5. Impactos da cultura e comportamento.

\begin{tabular}{lcc}
\hline \multicolumn{1}{c}{ Questões } & $\begin{array}{c}\text { Concordam } \\
(\%)\end{array}$ & $\begin{array}{c}\text { Discordam } \\
(\%)\end{array}$ \\
\hline $\begin{array}{l}\text { Satisfação e interação dos funcionários } \\
\text { quanto ao uso do sistema }\end{array}$ & 87 & 13 \\
$\begin{array}{l}\text { Houve promoção de uma cultura de } \\
\text { utilização }\end{array}$ & 57 & 43 \\
$\begin{array}{l}\text { A adoção do sistema forçou a quebra } \\
\text { de paradigmas }\end{array}$ & 47 & 53 \\
Houve resistência quanto às mudanças & 67 & 33 \\
\hline
\end{tabular}

Fonte: dados da pesquisa (2006).

\subsection{Benefícios, objetivos estratégicos e suporte de outras tecnologias}

Neste tópico é discutido o quinto e último bloco de perguntas (24 a 29), o qual se referiu aos vieses estratégicos e benefícios gerais do ERP, conforme expostos na Tabela 6 da sequência. Da mesma forma, 
Tabela 6. Benefícios proporcionados pelo ERP.

\begin{tabular}{|c|c|c|c|c|c|}
\hline Itens de análise & Grande $(\%)$ & $\begin{array}{l}\text { Entre muita e } \\
\text { moderada (\%) }\end{array}$ & Mediana $(\%)$ & $\begin{array}{c}\text { Entre mediana e } \\
\text { pouca }(\%)\end{array}$ & Pouca $(\%)$ \\
\hline Suprir as carências nos relatórios & 17 & 27 & 17 & 17 & 23 \\
\hline Melhor integração dos processos & 70 & 13 & 17 & 0 & 0 \\
\hline Melhor desempenho em outras áreas & 7 & 17 & 17 & 20 & 40 \\
\hline Melhor apoio às estratégias & 23 & 30 & 30 & 17 & 0 \\
\hline Racional./flexibilização no trabalho & 37 & 17 & 20 & 20 & 6 \\
\hline Ambiente participativo & 13 & 10 & 37 & 20 & 20 \\
\hline Banco de dados único e apoio decisão & 17 & 27 & 13 & 13 & 30 \\
\hline Redução de custos/retrabalho & 11 & 20 & 23 & 23 & 23 \\
\hline Padronização/adaptação dos processos & 50 & 33 & 7 & 10 & 0 \\
\hline Integração da cadeia de suprimentos & 30 & 17 & 23 & 17 & 23 \\
\hline Maior eficiência e competitividade & 37 & 37 & 17 & 10 & 0 \\
\hline Resultados satisfatórios/clientes/fornec. & 10 & 30 & 20 & 37 & 3 \\
\hline Visão para as melhores práticas & 37 & 20 & 13 & 23 & 7 \\
\hline Melhorou imagem da empresa & 7 & 10 & 20 & 13 & 50 \\
\hline
\end{tabular}

Fonte: dados da pesquisa (2006).

priorizou-se pela análise dos itens que tiveram entre moderada e grande importância em percentuais.

Melhor integração dos processos (70\%). Distinguiu-se anteriormente como uma das maiores dificuldades mencionadas, mas ao mesmo tempo foi apontada como um dos benefícios supremos do ERP. 0 mesmo ocorreu com a padronização e adaptação dos processos (50\% e 33\%), avaliadas como de grande dificuldade, mas foi justamente um dos quesitos a que se atribuiu um vasto benefício. Percebe-se que embora reconheçam as vantagens essenciais do sistema, as empresas ainda encontram muitos obstáculos para usufruí-las. Outras respostas que se destacaram:

- Visão das melhores práticas de negócios (37\% e 20\%); Racionalização/flexibilidade (37\%); Maior eficiência e competitividade (37\% e 37\%); Gestão da cadeia de suprimentos (30\%); Suprir as carências nos relatórios (27\%); e Apoio nas estratégias de negócios (30\% e 23\%).

Quanto aos itens citados como de pouca ou entre pouca e mediana importância, destacaram-se:

- Melhor desempenho do ERP em áreas nas quais não está totalmente integrado. Revelou-se insignificante para $40 \%$, provavelmente devido ao processo de implantação estar ainda numa fase incipiente nessas áreas, ou devido ao próprio uso de tecnologias adicionais de apoio. Em compasso a esse questionamento, identificou-se na pesquisa que 13\% não utilizam o ERP no gerenciamento da fábrica. Dos $87 \%$ que possuem o sistema no ambiente fabril, 38\% julgaram de extraordinária importância no auxílio ao PCP. Quanto a redução de custos e retrabalhos, 31\% não avaliaram de maneira positiva;

- Utilização de um banco de dados único (30\%). Embora tenha representado um menor percentual, os teóricos asseveram que um dos maiores benefícios vislumbrados pelas empresas é o de que essas tecnologias possam, cada vez mais, extrair e filtrar as informações geradas nos diversos sistemas e subsistemas da organização e integrá-las num núcleo único de negócios; e

- Resultados satisfatórios com clientes e fornecedores (37\%). Considerou-se conflitante, uma vez que quando inquiridas sobre os resultados do atendimento aos clientes, $88 \%$ alcançaram ganhos satisfatórios, com efeitos negativos para somente $12 \%$ delas. Por tratar-se de um sistema focado nos benefícios internos da organização, para 50\% ele nada acrescentou em termos de melhor imagem externa, nem tampouco contribuiu para um ambiente mais participativo.

\section{Considerações finais}

A implantação de ERPs ainda é na atualidade um assunto de extrema relevância, como demonstra a contínua preocupação com que as organizações adquirem e implantam novos sistemas, ou migram de um para outro.

As pesquisas empíricas comprovam que muitos projetos falham porque não são eficazmente conduzidos. Há empresas que contratam consultorias para apoiar a implantação, enquanto outras adotam práticas próprias e não consideram todos os riscos e variáveis envolvidos. Trata-se de um projeto arrojado, arriscado, demanda longo tempo, envolve elevadas somas financeiras e exige um absoluto comprometimento gerencial e organizacional.

Constatou-se que os resultados dessa pesquisa atenderam com êxito os objetivos propostos. Buscou-se abranger ao máximo todos os aspectos que impactam num projeto de implantação, além de confrontar dados com o descrito na literatura. Muitos dados corroboraram a fundamentação teórica, outros apresentaram-se distintamente do preconizado. Nesse viés, estruturou-se o Quadro 4, sumarizando as principais constatações. 
Quadro 4. Síntese dos resultados.

\begin{tabular}{|l|l|}
\hline \multicolumn{1}{|c|}{ Dimensões } & \multicolumn{1}{c|}{ Principais evidências } \\
\hline $\begin{array}{l}\text { Projeto, estrutura } \\
\text { e funcionalidades }\end{array}$ & $\begin{array}{l}\text { lnsuficiência na integração, adequação aos } \\
\text { processos de negócios e peculiaridades de } \\
\text { legislação; Dificuldades da parametrização } \\
\text { e customização; Carência de conhecimento } \\
\text { em relação às funcionalidades e objetivos } \\
\text { do sistema, o que pode ser ocasionado pela } \\
\text { própria resistência das pessoas em usá-lo } \\
\text { efetivamente. }\end{array}$ \\
\hline Estratégicos & $\begin{array}{l}\text { Incompatibilidade com as estratégias } \\
\text { competitivas globais. }\end{array}$ \\
\hline Operacionalização & $\begin{array}{l}\text { Dificuldade de apresentar uma interface de uso } \\
\text { simples e descomplicado para o usuário, além } \\
\text { da descrença quanto aos dados e informações } \\
\text { geradas. }\end{array}$ \\
\hline $\begin{array}{l}\text { Fator humano e } \\
\text { comportamental }\end{array}$ & $\begin{array}{l}\text { É crucial o enaltecimento das pessoas, } \\
\text { avaliando-se o comportamento, engajamento } \\
\text { e cultura organizacional. }\end{array}$ \\
\hline $\begin{array}{l}\text { Gerência, equipes } \\
\text { e treinamentos }\end{array}$ & $\begin{array}{l}\text { Prioriza-se a integração de equipes, } \\
\text { participação gerencial, direção e treinamento } \\
\text { contínuo. }\end{array}$ \\
\hline
\end{tabular}

Fonte: elaborado pelos autores (OLIVEIRA, 2006).

Considerando a crescente utilização dos ERPs no segmento industrial, denota-se a importância da continuidade de pesquisas aprofundadas que abordem especificamente as tecnologias complementares do ERP, com destaque para CRM, Workflow, EDI, Bl e SCM, cujas ferramentas tecnológicas consolidam-se cada vez mais nas organizações.

Outras lacunas observadas e carentes de pesquisas relacionam-se à tecnologia móvel e ao uso remoto do ERP pela internet. Referenciando as aplicações industriais, onde se concentra a maior complexidade operacional desses sistemas, sugere-se ainda novos estudos relacionados a soluções mais específicas, ou funcionalidades focadas para as particularidades de cada tipo de indústria. Nesse sentido, sugere-se também estudos e levantamentos voltados para avaliação da utilização, por exemplo, de módulos de Planejamento e controle de chão de fábrica, com programação avançada e que possam ser integradas (maior desafio) ao ERP.

\section{Referências}

ALOINI, D.; DULMIN, R.; MININNO, V. Risk management in ERP project introduction: Review of the literature. Information \& Management, v. 44, n. 6, p. 547-567, 2007.

AVISON, D.; MALAURENT, J. Impact of cultural differences: A case study of ERP introduction in China. International Journal of Information Management, v. 27, n. 5, p. 368-374, 2007.

CALISIR, F.; CALISIR, F. The relation of interface usability characteristics, perceived usefulness, and perceived ease of use to end-user satisfaction with enterprise resource planning (ERP) systems. Computers in Human Behavior, v. 20, n. 4, p. 505-515, 2004. http://dx.doi.org/10.1016/j. chb.2003.10.004
CAVAlCANTI, M. (Coord.). Gestão Estratégica de Negócios: Evolução, cenários, diagnóstico e ação. São Paulo: Pioneira Thomson Learning, 2001.

CHOU, S. W.; CHANG, C. Y. The implementation factors that influence the ERP (enterprise resource planning) benefits. Decision Support Systems, v. 46, n. 1, p. 149-157, 2008. http://dx.doi.org/10.1016/j.dss.2008.06.003

COMPUTER WORLD. Mercado busca ERP mais adaptável. Computer World, São Paulo, mar. 2005.

CORREAA, H. L.; GIANESI, I. G. N.; CAON, M. Planejamento programação e controle da produção. 4. ed. São Paulo: Atlas, 2001.

CORTÊS, P. L.; LEMOS, M. T. S. Aspectos comportamentais na implantação de sistemas integrados de gestão ERP. Revista GEPROS, v. 4, n. 1, p. 83-100, 2009.

DAVENPORT, T. H. Reengenharia de processos: Como inovar na empresa através da tecnologia da informação. 2. ed. Rio de Janeiro: Campus, 1994.

EXAME. Melhores e maiores. As 500 maiores empresas do Brasil. Exame, São Paulo, abr. 2005.

FIAMENGUE NETO, A. Modismos gerenciais e cultura organizacional: um estudo de caso sobre a adoção de sistemas ERP. 2004. Dissertação (Mestrado em Desenvolvimento Regional e Meio Ambiente)-Centro Universitário de Araraquara, Araraquara, 2004.

FONTANA, R. M. Análise do processo de mudança organizacional a partir de um modelo baseado na teoria da complexidade: Aplicação na implantação de sistemas ERP. 2006. Dissertação (Mestrado em Engenharia de Produção e Sistemas)-Universidade Católica do Paraná, Curitiba, 2006.

FORTULAN, M. R.; GONÇALVES FILHO, E. V. Uma proposta de aplicação de Business Intelligence no chão de fábrica. Gestão \& Produção, v. 12, n. 1, p. 55-66, 2005. http:// dx.doi.org/10.1590/S0104-530X2005000100006

GAMBÔA, F. A. R.; CAPUTO, M. S.; BRESCIANI FILHO, E. Método para gestão de riscos em implementações de sistemas ERP baseado em fatores críticos de sucesso. Revista de Gestão da Tecnologia e Sistemas de Informação, v. 1, n. 1, p. 45-62, 2004.

GlL, A. C. Métodos e técnicas de pesquisa social. São Paulo: Atlas, 1999.

HAMMER, M. Guarda-Chuva - As ferramentas de melhoria do desempenho operacional têm de atender a um objetivo: o gerenciamento de processos. lsso evita a dispersão de recursos e a rivalidade entre departamentos. Revista HSM Management, v. 36, n. 34, p. 81-85,set-out. 2002.

JACOBS, F. R.; BENDOLY, E. Enterprise resource planning: Developments and directions for operations management research. European Journal of Operational Research, v. 146, n. 2, p. 233-240, 2002.

JESUS, R. G.; OLIVEIRA, M. 0. F. Implantação de sistemas ERP: Tecnologia e pessoas na implantação do SAP $\mathrm{R} / 3$. Revista de Gestão da Tecnologia e Sistemas de Informação, v. 3, n. 3, p. 315-330, 2007.

KRUSE, G. See no evil, hear no evil, speak no evil: The reality about enterprise resource planning implementations is often shrouded in mistruths. The IET Manufacturing Engineer, v. 85, n. 2, p. 40-43, 2006.

LAKATOS, E. M.; MARCONI, M. A. Fundamentos de Metodologia científica. 4. ed. São Paulo: Atlas, 2001.

LAURINDO, F. J. B. Tecnologia da Informação. São Paulo: Futura, 2002 a.

LAURINDO, F. J. B. et al. 0 papel da tecnologia da informação (TI) na estratégia das organizações. Gestão \& Produção, v 8, n. 2, p. 160-79, 2001. 
LAURINDO, F. J. B. et al. Selecionando uma aplicação de tecnologia da informação com enfoque na eficácia: Um estudo de caso de um sistema para PCP. Gestão \& Produção, v. 9, n. 3, p. 377-396, 2002 b.

LAW, C. H. C.; NGAl, W. T. E. ERP systems adoption: An exploratory study of the organizational factors and impacts of ERP success. Information \& Management, v. 44, n. 4, p. 418-432, 2007.

LUNA, S. V. Planejamento de pesquisa. São Paulo: Educ, 2002.

MACÊDO, A. F. P. Análise da influência de sistemas ERP na contabilidade: um estudo de caso nas companhias de saneamento da Paraíba e Rio Grande do Norte. 2005. $132 \mathrm{f}$. Dissertação (Mestrado Multiinstitucional e Inter-Regional em Ciências Contábeis)-Universidade da Paraíba, João Pessoa, 2005.

MELLO, L. C. B.; BANDEIRA, R. A. M. Lições aprendidas sobre a implementação de sistemas ERP: estudo de casos múltiplos em empresas líderes de mercado. ln: SIMPOSIO DE ENGENHARIA DE PRODUÇÃO, 14., 2007, Bauru. Anais... Bauru: SIMPEP, 2007.

MORGADO, F. Dificuldades operacionais causadas pela falta de alinhamento dos sistemas ERP com os processos de negócios: múltiplos estudos de casos em concessionárias de veículos. Revista GEPROS, v. 2, n. 2, p. 137-148, 2007.

NORRIS, G. et al. E-Business e ERP: Transformando as empresas. Rio de Janeiro: Qualitymark, 2001.

OLIVEIRA, L. S. Um estudo sobre os principais fatores na implantação de sistemas ERP. 2006. 154 f. Dissertação (Mestrado em Engenharia de Produção)-Universidade Tecnológica Federal do Paraná, Ponta Grossa, 2006.

PADILHA, T. C. C.; MARINS, F. A. S. Sistemas ERP: Características, custos e tendências. In: ENCONTRO NACIONAL DE ENGENHARIA DE PRODUÇÃO, 22., 2002, Curitiba. Anais... Curitiba: ENEGEP, 2002.

REA, L. M.; PARKER, R. A. Metodologia da Pesquisa: do planejamento à execução. São Paulo: Pioneira, 2000.

ROCKART, J. F. Chief executives define their own data needs. Harvard Business Review, v. 57, n. 2, p. 81-92, 1979.

SACCOL, A. Z. et. al. Avaliação do impacto dos sistemas ERP sobre variáveis estratégicas de grandes empresas no Brasil. Revista de administração contemporânea, v. 8, n. 1, 2004. http://dx.doi.org/10.1590/S1415-65552004000100002

SAMMON, D.; ADAM, F. Project preparedness and the emergence of implementation problems in ERP projects. Information \& Management, v. 47, n. 1, p. 01-08, 2010. http://dx.doi.org/10.1016/j.im.2009.09.002
SCHMITT, C. A. Sistemas Integrados de Gestão Empresarial: Uma contribuição no estudo do comportamento organizacional e dos usuários na implantação de sistemas ERP. 2004. Tese (Doutorado em Engenharia da Produção)-Universidade Federal de Santa Catarina, Florianópolis, 2004.

SILVA, A. L. M. R. A influência do treinamento de usuários na aceitação de sistemas ERP em empresas no Brasil. 2005. Dissertação (Mestrado em Administração)-Universidade Federal do Rio de Janeiro, Rio de Janeiro, 2005.

SOUZA, C. A. Sistemas Integrados de Gestão Empresarial: Estudos de casos de implementação de Sistemas ERP. 2000. Dissertação (Mestrado em Administração)-Universidade de São Paulo, São Paulo, 2000.

SOUZA, C. A. et. al. Paradoxo da produtividade: análise de evidências em um estudo de caso. Revista INGEPRO, v. 2, n. 7, 2010.

TURBAM, E.; McLEAN, E.; WETHERBE, J. Information Technology for management: Transforming business in the digital economy. 3. ed. New York: John Wiley \& Sons Inc., 2002.

UMBLE, E. J.; HAFT, R. R.; UMBLE, M. Enterprise resource planning: Implementation procedures and critical success factors. European Journal of Operational Research, v. 146, n. 2, p. 241-257, 2003.

WANG, T. G. E. et. al. The consistency among facilitating factors and ERP implementation success: A holistic view of fit. The journal of Systems and software, v. 81, n. 9 , p. 1609-621, 2008.

XUE, Y. et. al. ERP implementation failures in China: Case studies with implications for ERP vendors. International Journal of Production Economics, v. 97, n. 3, p. 279-295, 2005.

YEN, R. H.; SHEU, C. Aligning ERP implementation with competitive priorities of manufacturing firms: An exploratory study. International Journal of Production Economics, v. 92, n. 3, p. 207-220, 2004.

\section{Agradecimentos}

Os autores agradecem a Capes pelo apoio financeiro concedido para a realização desta pesquisa, aos editores e aos revisores anônimos pelos valiosos comentários e contribuições.

\title{
A study on ERP system implementation: a survey at large industrial companies
}

\begin{abstract}
The large utilization of ERP systems has become the scope of discussion among specialists, researchers and professionals of the area, with the purpose of finding an answer for the success and failure cases on ERP implementation. This paper aimed to present an experimental study with the 50 biggest industrial companies with activities in Brazil in order to identify the main factors that contribute or hinder ERP implementation processes. This study was characterized by an applied and exploratory research. Besides the bibliographical survey, a structured questionnaire containing 29 questions was elaborated by the researchers and then responded by the IT (Information Technology) managers of the selected companies. Results showed that the factors concerning system functionality difficulties, customization, adjustment to business processes, and lack of support by ERP systems on global strategic plans were some of the points considered as the most complex by the companies. Other critical questions regarding users' intensive training; engagement of main leaderships; human, social and cultural factors were evaluated as of great importance.
\end{abstract}

\section{Keywords}

ERP systems. Implementation project. Critical success factors. Business processes. 
Apêndice A. Questionário da pesquisa.

Data:

Empresa:

Responsável pelas informações:

E-mail:

Prezado respondente, seguem as Instruções da pesquisa:

- Esta pesquisa está sub-dividida em 5 módulos, contendo ao todo 29 questões;

- Como a planilha está PROTEGIDA, basta clicar com o mouse em cada campo de resposta;

- Solicitamos a gentileza de nos devolver respondida esta pesquisa via formato

eletrônico, cujo prazo de encerramento está programado para o dia 06/03/2006.

- Os e-mails para o envio são: admlinsoli@yahoo.com.brou lindomar@utfpr.edu.br

- Salientamos que as informações declaradas nesta pesquisa, são para fins exclusivamente acadêmicos.

- Informe se desejam receber os resultados desta pesquisa $\quad \square$ SIM $\quad \square$ NÃO

\section{MÓDULO DE QUESTÕES N.1 - CARACTERIZAÇÃO DA EMPRESA}

1- Quanto ao número de funcionários:
$\square$ Menos de 500
$\square$ Entre 501 e 1000
Entre 1001 e 2000
$\square$ Acima de 2000

2- Quanto ao faturamento anual, (R\$ em milhões):
$\square$ De 10 até 50
De 50.001 até 120
$\checkmark$ Acima de 120

3- Quanto ao porte da Empresa:

$\square$ Médio
$\square$ Grande

4- Quanto ao Capital Social:
Nacional
$\square$ Multinacional
$\square$ Economia Mista

Outro

Nas questões abaixo (5 a 8) ordene, conforme a escala de importância, sendo, 5 para Maior importância e 1 para Menor importância:

Legenda de Avaliação:

5-Grande importância

4-Entre Muito e Moderada importância

3-Importância Mediana

2-Entre Mediana e Pouca Importância

1-Pouca Importância

5- Dificuldades em relação a custos, pessoas e adaptação do Sistema ERP:

$\square$ Adaptação do sistema à economia/legislação brasileira

$\checkmark$ Qualificação técnica das pessoas para trabalhar com o sistema

$\square$ ldentificação e adaptação aos processos de negócios

$\square$ Interface com outros módulos do sistema

$\square$ Altos custos de implantação

6- Dificuldades em relação as funcionalidades/operacionalização do sistema:

$\square$ Tornar o sistema Amigável e de fácil acesso: funcionalidades/Flexibilidade - Entender as rotinas

- Burocracia no preenchimento dos requisitos de formulários

Necessidade de outros programas Ex: (Excell, Access), para suprir as carências de relatórios gerenciais

$\square$ Processo de parametrização/customização

Implantação parcial, ou seja, ter que manter o sistema antigo funcionando paralelamente 
7- Dificuldades em relação a confiabilidade, atualizações e recursos oferecidos pelo sistema:

$\square 0$ sistema não oferece todos os recursos necessários ao negócio

Confiabilidade dos dados e informações geradas

$\square$ Tempo de resposta aos clientes

Atualizações do sistema (upgrades)

$\square$ Adaptação das melhores práticas gerenciais e organizacionais (Best Practices)

8- Dificuldades no relacionamento do Sistema ERP com os objetivos estratégicos da organização:

$\square$ Oferecer visão de longo prazo de resultado nos negócios e estar alinhado às estratégias competitivas

$\square$ Oferecer um relacionamento sustentável com os clientes

$\square$ Impulsionar a empresa para competir em escala global

Causar mudanças nos modelos gerenciais

$\square$ Adaptar o sistema ao crescimento do negócio e as novas tecnologias

Nas Questões (9 a 12), marque a opção que se aplica na empresa em relação:

9- As mudanças que foram necessárias para a implantação do sistema:

$\square$ Não aplicou-se a Reengenharia/redesenho de processos

$\square$ Houve a implantação e posteriormente readequou-se os processos

No ato da implantação do sistema realizou-se a Reengenharia dos processos, (deu-se ao mesmo tempo).

Primeiramente fez-se a Reengenharia dos processos e depois implantou-se o sistema

$\square$ Outra forma de implantação

10- A visão de que o Sistema ERP era necessário para a Empresa:

$\square$ Concordo plenamente

$\square$ Concordo parcialmente

Neutro

Discordo parcialmente

$\square$ Discordo plenamente

11- Ao grau de conhecimento dos usuários a respeito do Sistema ERP:

$\square$ Não ter muito conhecimento

$\square$ Ter um pleno conhecimento

12- A visão de que o Sistema ERP era uma Tendência:

$\square$ Concordo plenamente

$\square$ Concordo parcialmente

Neutro

Discordo parcialmente

Discordo plenamente

MÓDULO DE QUESTÕES N.3 - FASES DO PROJETO E ASPECTOS QUE CONTRIBUEM PARA ALCANÇAR OS RESULTADOS EMPRESARIAIS

Nas questões (13 a 17) marque a (s) opção (s) que se aplica (m) à empresa:

13- Quanto ao tipo de Sistema ERP que a empresa possui?
$\square$ SAP
1 ORACLE
MICROSOFT
DATASUL
MICROSIGA
1] Outro

14- Quais desses Módulos do Sistema ERP que suportam o negócio da empresa?
$\square$ Vendas/Previsão
$\square$ Faturamento
Fluxo de Processos
Gestão de Ativos
Folha de Pagamento
Gestão Financeira
Manutenção
] Recebimento Fiscal

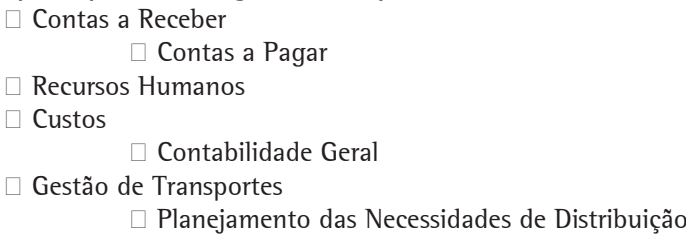

15- Quanto ao investimento total no projeto de implantação do Sistema ERP (R\$ 1.000,00):

$\square$ Entre 100 e 200

Entre 201 e 400

Entre 400 e 600

Entre 600 a $1.000 .000,00$

$\square$ Outro valor 
16- Quanto tempo envolveu todo o processo de implantação (em meses):
$\square$ Entre 6 a 12
Entre 13 e 24
- Entre 25 e 48
$\square$ Mais de 48

17- Com relação ao estudo de viabilidade de implantação, 5 fases são fundamentais:

Planejamento (abrangência do projeto;análise de custos e benefícios; análise de recursos disponíveis)

Avaliação estratégica (maior competitividade; melhoria nos processos; visão de longo prazo)

Identificação de oportunidades (identificar oportunidades e fatores competitivos; fatores

críticos de sucesso)

Avaliação econômico-financeira (análise dos investimentos em Hardware, Software, treinamento etc.)

Desenvolvimento de Recomendações e Comunicação (avaliação estratégica e econômica)
A empresa praticou integralmente todas estas fases
$\square$ A empresa praticou apenas parcialmente estas fases, Quais?

Nas questões abaixo (18 e 19) ordene, conforme a escala de importância, sendo, 5 para Maior importância e 1 para Menor importância:

18- Quanto ao envolvimento e participação no projeto do Sistema ERP quando foi implantado:

$\square$ Houve participação efetiva de todos os usuários "chaves" (equipe) na elaboração do projeto e implantação

$\square$ Houve participação das gerências e da alta direção no projeto

$\square$ Ficou claramente definido os objetivos e metas esperadas pela empresa

$\square$ Houve redução no número de funcionários

$\square 0$ projeto foi concluído dentro do prazo esperado

19- Considerando-se alguns fatores que favorecem uma implantação bem sucedida:

$$
\begin{aligned}
& \square \text { Implantação planejada por módulos } \\
& \square \text { Implantação total (Aquisição de pacotes de Software) } \\
& \square \text { Contratação de uma consultoria para implantação } \\
& \square \text { Cumprir o orçamento total planejado para a implantação } \\
& \square \text { Treinamento prévio dos funcionários }
\end{aligned}
$$

MÓDULO DE QUESTÕES N.4 - INFLUÊNCIA DOS ASPECTOS CULTURAIS

COMPORTAMENTAIS E TREINAMENTOS NO USO EFICAZ DO SISTEMA

Nas Questões (20 e 21) marque somente uma opção escolhida:

20- Quanto aos investimentos anuais em treinamentos com o Sistema ERP: (R\$ 1,00)

$\square$ Menos de 70.000

$\square$ Entre 71 e 100.000

Entre 101 e 200.000

- Entre 201 e 500.000

$\square$ Outro valor

21- Quanto a Interação e Aculturação dos funcionários com o uso do Sistema ERP:

$\square$ Plenamente Satisfeitos

$\checkmark$ Satisfeitos

$\square$ Insatisfeitos

Plenamente lnsatisfeitos 
Nas Questões (22 e 23) pode escolher e marcar mais de uma opção:

22- $\quad \square$ Ainda com relação ao comportamento dos usuários:

$\square$ As pessoas apresentam resistências com as mudanças causadas pelo sistema

$\square$ A cultura de utilização do sistema foi amplamente divulgada pela empresa

$\square$ A implantação do ERP trouxe incerteza e insegurança pela inovação

$\square$ Mudou a interação entre as pessoas e grupos (mudança dos limites de autoridade e autonomia)

$\square$ Quebrou paradigmas

23- Quanto ao treinamento dos funcionários:

$\square$ Dificuldade dos usuários chaves no repasse das informações aos outros funcionários da sua área

$\square$ A falta de treinamento influencia na obtenção de resultados eficazes do sistema

$\square$ Quando da implantação, foi considerado o nível de treinamento necessário aos usuários

$\square$ Houve treinamento em todas as fases do projeto

$\square$ Houve formação de grupos na implantação e que depois continuaram apoiando os outros usuários

\section{MÓDULO DE QUESTÕES N.5 - OS BENEFÍCIOS DO SISTEMA ERP E O SUPORTE DE} OUTROS SISTEMAS E TECNOLOGIAS EXISTENTES

24- Quais desses sistemas e/ou Ferramentas de Tl que a empresa utiliza além do ERP?

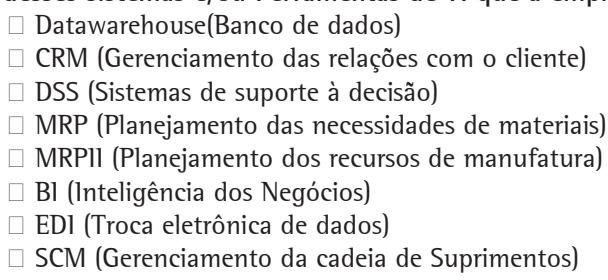

Nas questões abaixo (25 a 29) ordene, conforme a escala de importância, sendo, 5 para Maior importância e 1 para Menor importância:

25- Quanto aos benefícios do Sistema ERP integrado, ou suportado por outros sistemas existentes:

$\square$ Supre as carências do sistema ERP quanto aos relatórios gerenciais e oferece maior informação

$\square$ Melhor integração dos processos de negócios, proporcionando resultados eficazes

$\square$ Melhor desempenho do ERP em áreas onde o sistema não está totalmente integrado

$\square$ Proporciona um melhor apoio às estratégias de negócios da empresa

$\square$ Melhor relacionamento com fornecedores e clientes, utilizando softwares específicos

26- Quanto aos principais benefícios alcançados nos processos de trabalhos e ambiente organizacional:

$\square$ Racionalização, flexibilidade, agilidade nas operações e nas formas de trabalhar

$\square$ Ambiente mais participativo e visão global dos negócios

$\square$ Utiliza um banco de dados único e apoia as decisões em tempo real

$\square$ Redução de custos, problemas operacionais e retrabalhos

$\square$ Padronização e integração dos processos de negócios

27- Quanto aos benefícios Estratégicos:

$\square$ Gestão Integrada da cadeia de Suprimentos

$\square$ Maior eficiência e competitividade para a organização

1 Trouxe resultados satisfatórios na relação com os clientes e fornecedores

$\square$ Visão voltada para as melhores práticas de negócios

Melhorou a imagem da Empresa no mercado

28- Com relação à utilização do Sistema ERP no gerenciamento da fábrica:

$\square$ Melhora os processos produtivos e aumenta a produtividade

$\square$ Estabelece uma integração com outros planos da empresa, como: MKT, Vendas, Finanças.

Melhorou a comunicação dos setores produtivos

$\square$ Reduz os custos de produção

$\square$ Auxilia no planejamento e controle da produção, alocando de forma eficaz os recursos produtivos

29- Em relação ao atendimento dos clientes: Marque a opção que melhor representa os os resultados ocorridos:

$\square 0$ resultado foi extremamente negativo

$\square$ Houve de certa forma, resultados negativos

Regular

Houve algum resultado satisfatório

$\checkmark$ Houve grandes resultados satisfatórios

Finalmente foram concluídas todas as respostas, muito obrigado pela sua colaboração!!

Questões adaptadas de Cavalcantti (2001), Schmitt (2004), Souza e Zwicker (2000). 